\title{
Study of Aminoglycoside Resistance Genes in Enterococcus and Salmonella Strains Isolated From Ilam and Milad Hospitals, Iran
}

\author{
Nasser Samadi ${ }^{1}$; Iraj Pakzad ${ }^{1,2}$; Alireza Monadi Sefidan ${ }^{3}$; Hasan Hosainzadegan ${ }^{4, *}$; Asghar \\ Tanomand $^{4}$ \\ ${ }^{1}$ Department of Microbiology, Faculty of Medicine, Ilam University of Medical Sciences, Ilam, IR Iran \\ ${ }^{2}$ Clinical Microbiology Research Center, Ilam University of Medical Sciences, Ilam, IR Iran \\ ${ }^{3}$ Department of Microbiology, Tehran University of Medical Sciences, Tehran, IR Iran \\ ${ }^{4}$ Department of Basic Sciences, Faculty Of Medicine, Maragheh University of Medical Science, Maragheh, IR Iran \\ ${ }^{*}$ Corresponding author: Hasan Hosainzadegan, Department of Basic Sciences, Faculty Of Medicine, Maragheh University of Medical Science, Maragheh , IR Iran. Tel: +98-4137276364, \\ Fax:+98-4137276363, E-mail: hasanhosainy122@yahoo.com
}

Received: February 9, 2014; Revised: April 26, 2014; Accepted: May 11, 2014

Background: Aminoglycosides are a group of antibiotics that have been widely used in the treatment of life-threatening infections of Gram-negative bacteria.

Objectives: This study aimed to evaluate the frequency of aminoglycoside resistance genes in Enterococcus and Salmonella strains isolated from clinical samples by PCR.

Materials and Methods: In this study, 140 and 79 isolates of Enterococcus and Salmonella were collected, respectively. After phenotypic biochemical confirmation, 117 and 77 isolates were identified as Enterococcus and Salmonella, respectively. After the biochemical identification of the isolates, antibiotic susceptibility for screening of resistance was done using the Kirby-Bauer method for gentamicin, amikacin, kanamycin, tobramycin and netilmycin. DNA was extracted from resistant strains and the presence of acc (3)-Ia, aac ( $3^{\prime}$ )-Ib, acc (6)-IIa ,16SrRNA methylase genes (armA and rat) was detected by PCR amplification using special primers and positive controls.

Results: Enterococcus isolates have the highest prevalence of resistance to both kanamycin and amikacin (68.4\%), and Salmonella isolates have the highest prevalence of resistance against kanamycin (6.9\%). Ninety-three and 26 isolates of Enterococcus and Salmonella at least were resistant against one of the aminoglycosides, respectively. Moreover, $72.04 \%, 66.7 \%$, and $36.6 \%$ of the resistant strains of Enterococcus had the aac (3')-Ia, aac (3')-IIa, and acc (6')-Ib genes, respectively. None of the Salmonella isolates have the studied aminoglycoside genes. Conclusions: Our results indicate that acetylation genes have an important role in aminoglycoside resistance of the Enterococcus isolates from clinical samples. Moreover, Salmonella strains indicate very low level of aminoglycoside resistance, and aminoglycoside resistance genes were not found in Salmonella isolates. These results indicate that other resistance mechanisms, including efflux pumps have an important role in aminoglycoside resistance of Salmonella.

Keywords: Enterococcus; Salmonella; Aminoglycoside; Genes

\section{Background}

The increasing clinical frequency of antibiotic-resistant pathogens isolating from hospitals is one of the important health care issues all over the world. Studying of resistance determinants with molecular and genetic methods have a critical role in understanding, controlling, and spreading of resistant pathogens. Aminoglycosides are the most frequently used antibiotic agents in the treatment of infections by both Gram-negative and Gram-positive bacteria. This group of antibiotics acts by binding to the ribosomes of bacteria and in turn interferes with protein synthesis (1-3).

The main strategy of resistance against aminoglycosides in clinical bacterial isolates is the production of modifying enzymes, such as Aminoglycoside Phosphoryltransferase (APH), Aminoglycoside Acetyltransferase (AAC), and Aminoglycoside Nucleotidyltransferase (ANT) $(4,5)$. The APHs and ANTs are the bisubstrate enzymes, which facilitate the transfer of the $\gamma$-phosphate and nu- cleotide monophosphate, respectively, from a nucleotide substrate to the hydroxyl groups of aminoglycoside antibiotics, while AACs acetylate amino groups derived from Acetyl Coenzyme A (acetyl-CoA) (6). Moreover, aac (6')-I confers resistance to tobramycin and amikacin, aac ( $\left.6^{\prime}\right)$-II and ant ( $\left.2^{\prime \prime}\right)$-I inactivate tobramycin and gentamicin, and amikacin is the substrate of aph (3')-VI (7).

The 16S rRNA methylase confers high-level resistance to 4, 6-substituted deoxystreptamines, including, arbekacin, amikacin, kanamycin, tobramycin and gentamicin, by posttranscriptional methylation of 16S rRNA leading to loss of affinity for aminoglycosides (8). Despite the existence of more than 85 aminoglycoside-modifying enzymes, only a limited number of them, ANT(2")-I, AAC(6')-I, AAC(3)-I, AAC(3)-II, AAC(3)-III, AAC(3)-IV and AAC(3)-VI, appear to have been undergoing selection process and causing the majority of aminoglycoside resistance (9).

Copyright (C) 2015, Ahvaz Jundishapur University of Medical Sciences. This is an open-access article distributed under the terms of the Creative Commons Attribution-NonCommercial 4.0 International License (http://creativecommons.org/licenses/by-nc/4.0/) which permits copy and redistribute the material just in noncommercial usages, provided the original work is properly cited. 
Samadi $N$ et al.

\section{Objectives}

In different studies, the phenotypic and genotypic resistance of Enterococcus and Salmonella isolates against aminoglycosides has been reported from Iran and all over the world (10-17). This study aimed to investigate the occurrence of aminoglycoside resistance and the prevalence of the resistance-modifying enzyme genes, acc(3)-Ia, aac(6 $\left.6^{\prime}\right)$ Ib, acc(3)-IIa, armA and rat in Enterococcus and Salmonella strains isolated from two hospitals in Iran (Imam Khomeni , Ilam and Milad, Tehran, Respectively).

\section{Materials and Methods}

All of the culture media were purchased from Himedia laboratories (India), and Polymerase Chain Reaction (PCR) materials were also purchased from CinnaGen Company (Iran). Gentamicin (10 $\mu \mathrm{mol} / \mathrm{L})$, amikacin (30 $\mu \mathrm{mol} / \mathrm{L})$, kanamycin $(30 \mu \mathrm{mol} / \mathrm{L})$, and tobramycin $(10$ $\mu \mathrm{mol} / \mathrm{L}$ ) were obtained from Himedia, and netilmicin (30 $\mu \mathrm{mol} / \mathrm{L}$ ) was obtained from Mast laboratories (Mast Diagnostic, Merseyside, UK).

\subsection{Bacterial Isolates}

Enterococcus and Salmonella isolates were collected from Imam Khomeni and Milad hospitals of Ilam and Tehran, Respectively) during a 6-month period (2010). Antibiotic susceptibility was determined by the disk diffusion method. Moreover, antimicrobial susceptibility was determined using the disk diffusion method (Kirby-bauer) against gentamicin $(10 \mu \mathrm{mol} / \mathrm{L})$, amikacin $(30 \mu \mathrm{mol} / \mathrm{L})$, kanamycin $(30 \mu \mathrm{mol} / \mathrm{L})$, and tobramycin $(10 \mu \mathrm{mol} / \mathrm{L})$, according to the guidelines of the Clinical and Laboratory Standards Institute (CLSI).

\subsection{Polymerase Chain Reaction Studies}

Detection of aminoglycoside resistance genes, including acc(3)-Ia, aac(6')-Ib, acc(3)-IIa, and 16S rRNA methylase (armA and rat) were detected by PCR. A fresh bacterial col- ony was suspended in $100 \mu \mathrm{L}$ of sterile distilled water and boiled at $100^{\circ} \mathrm{C}$ for 10 minutes. After centrifugation, $3 \mathrm{~mL}$ of supernatant was used for PCR assays with the primers described in Table 1. Amplification of DNA was performed in a thermal cycler (Eppendrof, Germany). Polymerase chain reaction elongation times and temperature conditions were indicated in Tables 1 and 2. Moreover, PCR products were electrophoresed in $1.5 \%$ agarose gels and visualized under UV light. The PCR product of 16S rRNA methylase was then purified with the QIA quick PCR purification kit (QIAGEN, Inc., Chatsworth, CA, USA) and sequenced on both strands with an ABI PRISM 3100 (Applied Biosystems) genetic analyzer (18-20). The sequences were compared with those in GenBank nucleotide database.

\section{Results}

From a total of 140 and 79 isolates of Enterococcus and Salmonella collected presumptively, 117 and 77 isolates were identified and included as Enterococcus and Salmonella, respectively. Isolates were preserved in Tripticase Soy Broth (TSB) containing 20\% glycerol. The isolates were obtained with high percentages from specimens of urine, ulcer and sputum, with $87.2 \%, 6 \%$, and $3.4 \%$, respectively, after that $0.9 \%$ of the positive specimens were taken from the catheter, blood, ascites, and abscess (Table 3). Moreover, $46.2 \%(n=54)$ and $53.8 \%(n=63)$ of Enterococcus were from male and females, respectively. Ninety-three out of 117 strains of Enterococcus were resistant to aminoglycosides. Resistant strains of Enterococcus have the highest prevalence of resistance against both kanamycin and amikacin ( $68.4 \%$ and $80 \%$ of the cases, respectively), and after that tobramycin with $42.7 \%$ (50 cases) and gentamicin with $28.2 \%$ (33 cases), respectively. Salmonella isolates have the highest rate of resistance against kanamycin (6.9\%), and minor percentages of resistance against other 3 antibiotics. Ninety-three isolates of Enterococcus and 26 isolates of Salmonella at least were resistant against one of the aminoglycosides using the disk diffusion method.

\begin{tabular}{|c|c|c|c|}
\hline Genes & Primer Sequence & M. W, bp & Reference \\
\hline aac (3)-Ia & & 484 & This study \\
\hline Forward & 5'-ATGGGCATC ATTCGCACA-3' & & \\
\hline Reverse & 5'-TCTCGGCTTGAACGAATTGT-3' & & \\
\hline $\operatorname{acc}\left(6^{\prime}\right)-I b$ & & 524 & This study \\
\hline Forward & 5'-ATGACTGAGCATGACCTTG-3' & & \\
\hline Reverse & 5'-AAG GGTTAG GCA ACA CTG-3' & & \\
\hline aac (3)-IIa & & 749 & This study \\
\hline Forward & 5'-CGGAAGGCAATAACGGAG-3' & & \\
\hline Reverse & 5'-TCGAACAGGTAGCACTGAG -3' & & \\
\hline $\operatorname{armA}$ & & 591 & AY220558 (1) \\
\hline Forward & 5'-AGGTTGTTTCCATTTCTGAG-3' & & \\
\hline Reverse & 5'-ТСТСТТССАТТСССТТСТСС-3' & & \\
\hline rat & & 585 & AB103506 (1) \\
\hline Forward & $5^{\prime}$-CCCAAACAGACCGTAGAGGC-3' & & \\
\hline Reverse & 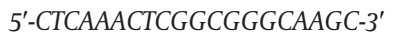 & & \\
\hline
\end{tabular}


Table 2. Polymerase Chain Reaction of aac(3)-Ia, aac(6')-Ib, aac(3)IIa, armA, rat Genes

\begin{tabular}{lc}
\hline Cycle Counts & Temperature and Time \\
\hline $\mathbf{1}$ & \\
\hline Primary denaturation & $94^{\circ} \mathrm{C}, 5 \mathrm{~min}$ \\
\hline $\mathbf{2}$ & \\
\hline Denaturation & $94^{\circ} \mathrm{C}, 45 \mathrm{~s}$ \\
Annealing & \\
\hline aac(3)-Ia & $55^{\circ} \mathrm{C}, 30 \mathrm{~s}$ \\
\hline aac(6')-Ib & $53^{\circ} \mathrm{C}, 30 \mathrm{~s}$ \\
\hline aac(3)-Ila & $55^{\circ} \mathrm{C}, 30 \mathrm{~s}$ \\
\hline armA & $53^{\circ} \mathrm{C}, 30 \mathrm{~s}$ \\
\hline rat & $56^{\circ} \mathrm{C}, 30 \mathrm{~s}$ \\
\hline Primary extension & $72^{\circ} \mathrm{C}, 1 \mathrm{~min}$ \\
\hline Final extension & $72^{\circ} \mathrm{C}, 10 \mathrm{~min}$ \\
\hline
\end{tabular}

4.1. Polymerase Chain Reaction for Detection of Aminoglycoside Resistance Genes

All of 119 of both Enterococcus and Salmonella isolates, which were resistant to aminoglycosides in disk diffusion were tested for the detection of acc(3)-Ia, aac( $\left.6^{\prime}\right)-\mathrm{Ib}$, acc(3)-IIa, 16S rRNA methylase (armA and rat). Also, $72.04 \%$ (67), 66.7\% (62), and 36.6\% (34) of the resistant strains of Enterococcus had the aac ( $\left.3^{\prime}\right)$-Ia, aac $\left(3^{\prime}\right)$-IIa, and aac $\left(6^{\prime}\right)$-Ib genes, respectively. All of the resistant isolates of Enterococcus were negative for both armA and rat genes, and none of the Salmonella isolates have the studied aminoglycoside genes, because of this fact other data relating to Salmonella isolates were not reported in later sections of article. Mono and multi-aminoglycoside gene resistance patterns were indicated in Enterococcus isolates in Table 4. Furthermore, a sample of electrophoresis profile of the PCR products of aminoglycoside resistant enterococci was indicated in Figure 1.

Table 3. Frequency of Enterococcus Isolates Based on the Samples a, b

\begin{tabular}{lcccccccc}
\hline Sample & Urine & Wound & Sputum & Catheter & Blood & Ascites & Skin Abscess & Total \\
\hline Frequency & $102(87.2)$ & $7(6)$ & $4(3.4)$ & $1(0.9)$ & $1(0.9)$ & $1(0.9)$ & $1(0.9)$ & $117(100)$ \\
\hline
\end{tabular}

a All of the Salmonella isolates were from stool samples.

${ }^{b}$ Data are presented as No.(\%).

Table 4. Mono and Multi-Aminoglycoside Gene Resistance Pattern in Enterococcus Isolates a, b, c

\begin{tabular}{|c|c|c|c|c|c|c|c|}
\hline \multirow{2}{*}{$\begin{array}{l}\text { Antibiotic Resistance } \\
\text { Phenotype }\end{array}$} & \multirow{2}{*}{$\begin{array}{c}\text { Percentage } \\
\text { of Resistance }\end{array}$} & \multicolumn{6}{|c|}{ Gene } \\
\hline & & aac (3)-Ia & aac (3)-IIa & $\operatorname{aac}\left(6^{\prime}\right)-$ Ib & IIa and Ib & $\operatorname{armA}$ & rat \\
\hline GM & $33(28.2)$ & $21(63.6)$ & $25(75.8)$ & $8(25.2)$ & $7(21.2)$ & 0 & 0 \\
\hline $\mathbf{K}$ & $80(68.4)$ & $59(73.8)$ & $53(66.2)$ & $30(37.5)$ & $17(21.2)$ & 0 & 0 \\
\hline AK & $80(68.4)$ & $53(66.2)$ & $56(70)$ & $22(27.5)$ & $15(18.8)$ & 0 & 0 \\
\hline ТОВ & $50(42.7)$ & $32(64)$ & $40(80)$ & $14(28)$ & $12(24)$ & 0 & 0 \\
\hline GM and $K$ & $33(28.2)$ & $21(63.6)$ & $25(75.8)$ & $8(24.2)$ & $7(21.2)$ & 0 & 0 \\
\hline GM and AK & $33(28.2)$ & $21(63.6)$ & $25(75.8)$ & $8(24.2)$ & $7(21.2)$ & 0 & 0 \\
\hline GM and TOB & $33(28.2)$ & $21(63.6)$ & $25(75.8)$ & $8(24.2)$ & $7(21.2)$ & 0 & 0 \\
\hline GM and $K$ and $A K$ & $33(28.2)$ & $21(63.6)$ & $25(75.8)$ & $8(24.2)$ & $7(21.2)$ & 0 & 0 \\
\hline GM \& K \& AK \& TOB & $33(28.2)$ & $21(63.6)$ & $25(75.8)$ & $8(24.2)$ & $7(21.2)$ & 0 & 0 \\
\hline$K$ and $A K$ and TOB & $46(39.3)$ & $30(65.2)$ & $36(78.3)$ & $12(26.1)$ & $10(21.7)$ & 0 & 0 \\
\hline AK and TOB & $48(41.3)$ & $31(64.6)$ & $38(79.2)$ & $13(27.1)$ & $11(22.9)$ & 0 & 0 \\
\hline K and TOB & $47(40.2)$ & $30(63.8)$ & $37(78.7)$ & $12(25.5)$ & $10(21.3)$ & & \\
\hline K and AK & $68(58.1)$ & $48(70.6)$ & $48(70.6)$ & $21(30.9)$ & $14(20.6)$ & 0 & 0 \\
\hline
\end{tabular}

a Abbreviations: GM, gentamicin; K, kanamycin; AK, amikacin; TOB, tobramycin.

$\mathrm{b}$ Percentage of resistant strains and percentage of genes have been calculated considering total count of isolates and total resistant strains, respectively.

${ }^{\mathrm{C}}$ All of the mono and multi-aminoglycoside gene resistance patterns in Salmonella isolates were zero or without any result. 
Figure 1. Electrophoresis Profile of the Polymerase Chain Reaction Products of Clinical Enterococcus Isolates Containing Aminoglycoside Resistance Genes

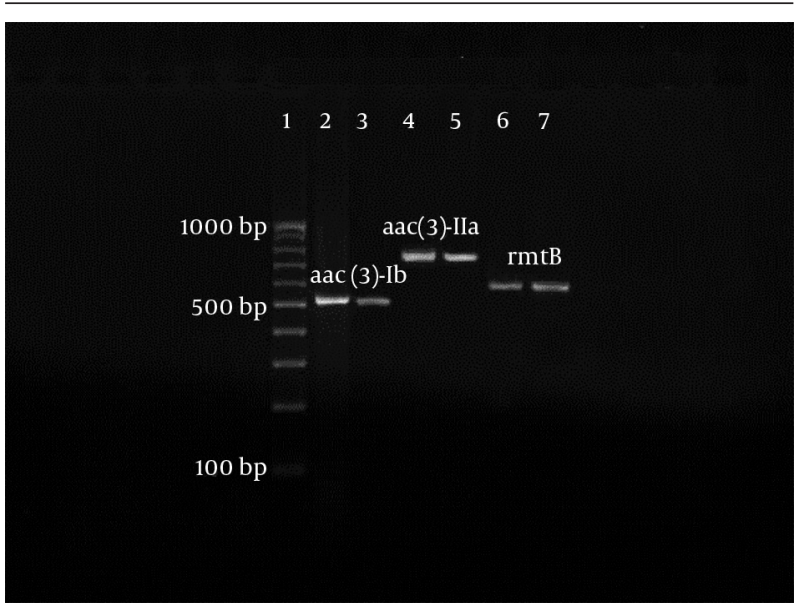

Lane 1: 100 base pair (bp) marker; lanes 2, 4 and 6: positive controls for aminoglycoside genes, Lanes 3, 5 and 7: clinical isolates containing aminoglycoside genes.

\section{Discussion}

There is no doubt that screening of resistance genes are very useful tools in epidemiologic tracing of genes between bacterial species, prediction of future outbreaks in different regions, treatment strategies and many other subjects in the treatment and control of bacterial diseases. Based on internet resources, we conducted first report of aminoglycoside resistance genes from Iranian clinical isolates of Enterococcus strains. We could not found 16sRNA modifying gene in studied isolates of Enterococcus and Salmonella. Enzymatic modification of aminoglycosides including phosphorylation, adenylation and acetylation of amine and hydroxyl groups are from most common methods of antibiotic resistance in bacteria (21). Among aminoglycoside modifying enzymes, aac (6')-Ib gene is more common and leads to tobramycin, kanamycin and amikacin resistance. This gene firstly identified in Klebsiella pneumonia isolates in 1986 (22). Although aminoglycoside modifying enzymes are the most common and major methods of resistance, 16S rRNA methylase-producing Gram-negative bacteria have been increasingly reported in recent years (23). This type of resistance is mediated by plasmids and is a new resistance mechanism in Enterobacteriaceae and non-fermentative Gramnegative bacilli. Comprehensive study of resistance patterns of isolates from different resources including environment, animals, and humans could help us to direct our treatment and control policies of infectious diseases, considering this point more than 95\% of Escherichia coli and enterococci isolates from common buzzards in one study showed that they are resistant to common antimicrobials such as streptomycin, tetracycline, ampicillin, chloramphenicol, gentamicin, kanamycin, etc. Because of the absence of direct antibiotic pressure in the world, this fact clearly indicates direct distribution of resistance genes from human life to other environments, which in turn helps to recycle such problems (24).

The witness for this claim is the frequent studies in which the presence of resistance, high-level aminoglycoside resistance, and other antibiotic resistance genes have been indicated in human, animals and food resources (25-28). Overall, there are scarce reports on aminoglycoside resistance genes in Salmonella species (13). There are little studies on resistance patterns of Enterococcus from Iran, and many of them have been focused on vancomycin and High-Level Gentamicin Resistant (HLGR) $(14,15,29)$; in one of the studies, the aac(6')-Ie-aph(2")-Ia gene were identified in $83 \%$ of Enterococcus faecalis and $100 \%$ of $E$. faecium HLGR isolates, respectively (29). Moniri et al. (16) in their study showed that aac (6')/aph (2") and esp, genes were found in $E$. fecalis isolates $68.4 \%$, and $61.1 \%$, respectively. They proposed a meaningful relationship between biofilm formation and possession of Enterococcal Surface Protein (ESP) and aac (6')/aph (2") genes. Vaziri et al. (30) in their study of the prevalence of aminoglycoside-modifying enzyme genes (aac (6')-I, aac (6')-II, ant (20)-I, aph (3')-VI) in 250 clinical Pseudomonas aeruginosa isolates found that aac (6')-II (36\%) was the most frequently identified gene in phenotypic resistant isolate. Because of widespread distribution of aminoglycoside resistance, related common genes with new resistance mechanisms were evaluated in this study.

This study aimed to determine the prevalence of aminoglycoside resistance genes (acc (3)-Ia, aac (6'), acc (3)-IIaIb, armA, rat) in Enterococcus and Salmonella isolates from clinical samples of Milad (a 1000 bed Tehran hospital) and Ilam hospitals. Totally, 117 and 77 isolates of Enterococcus and Salmonella were collected and studied for the presence of mentioned genes. RmtB and ArmA genes are not identified in our studied isolates, these enzymes are belonging to a group of resistance genes calling $16 \mathrm{~S}$ rRNA-methylases (16S-RMTases) that are plasmid-mediated and until now 5 main types of ArmA, RmtA, RmtB, RmtC, and RmtD have been identified all over the world. RmtB has been reported from various Gram-negative bacterial species including K. pneumoniae, and K. oxytoca, isolated in Japan, South Korea, and Taiwan. Until now, 16SRMTases have been reported from at least 30 countries or regions, and worldwide distribution of these genes is considered in some studies as an alerting hint to healthcare officials (31), In china E. coli clinical isolates were reported highly resistant to gentamicin and etimicin, and the aminoglycoside-modifying enzyme, AAC(3)-II, seems to bea main type of E. coli strains resistance to aminoglycoside agents (32). Results of the current study similar to many other researches emphasizes on implementation of concise programs, including molecular methods from officials toward special regulations on resistance pattern of bacteria in hospital environments especially on apparently noncommon bacteria, such as Salmonella 
and Enterococci. Results of this study showed that in Enterococcus isolates, acetylation genes had an important role in resistance to aminoglycosides and because of a high frequency of aminoglycoside resistance in clinical Enterococcus isolates, the following suggestions have been recommended to health care professionals: 1- Prescription of aminoglycosides only after antibiogram, or prescription of amikacin, tobramycin and netilmycin in empirical treatment cases. 2- Evaluation of efflux pumps of MexAB-OprM, and aminoglycoside resistance genes in these strains. 3- Annual or 6 month reports and tracking of antibiograms with precise and suitable sensitive tests, especially on hospital acquired infection cases.

\section{Acknowledgements}

The authors would like to thank deputy of research and technology of Ilam University of Medical Sciences, Iran, for its financial support.

\section{Financial Disclosure}

This study has been granted and approved by research deputy of Ilam University of Medical Sciences.

\section{References}

1. Mingeot-Leclercq MP, Glupczynski Y, Tulkens PM. Aminoglycosides: activity and resistance. Antimicrob Agents Chemother 1999;43(4):727-37.

2. Kotra LP, Haddad J, Mobashery S. Aminoglycosides: perspectives on mechanisms of action and resistance and strategies to counter resistance. Antimicrob Agents Chemother. 2000;44(12):3249-56.

3. Fluit AC, Visser MR, Schmitz FJ. Molecular detection of antimicrobial resistance. Clin Microbiol Rev. 2001;14(4):836-71.

4. Shaw KJ, Rather PN, Hare RS, Miller GH. Molecular genetics of aminoglycoside resistance genes and familial relationships of the aminoglycoside-modifying enzymes. Microbiol Rev. 1993; 57(1):138-63.

5. Yamane K, Wachino J, Doi Y, Kurokawa H, Arakawa Y. Global spread of multiple aminoglycoside resistance genes. Emerg Infect Dis. 2005;11(6):951-3.

6. Toth M, Frase H, Chow JW, Smith C, Vakulenko SB. Mutant $\mathrm{APH}\left(2^{\prime \prime}\right)$-IIa enzymes with increased activity against amikacin and isepamicin. Antimicrob Agents Chemother. 2010;54(4):1590-5.

7. Poole K. Aminoglycoside resistance in Pseudomonas aeruginosa. Antimicrob Agents Chemother. 2005;49(2):479-87.

8. Yu FY, Yao D, Pan JY, Chen C, Qin ZQ, Parsons C, et al. High prevalence of plasmid-mediated 16S rRNA methylase gene rmtB among Escherichia coli clinical isolates from a Chinese teaching hospital. BMC Infect Dis. 2010;10:184.

9. Vakulenko SB, Mobashery S. Versatility of aminoglycosides and prospects for their future. Clin Microbiol Rev. 2003;16(3):430-50.

10. Hopkins KL, Escudero JA, Hidalgo L, Gonzalez-Zorn B. 16S rRNA methyltransferase RmtC in Salmonella enterica serovar Virchow. Emerg Infect Dis. 2010;16(4):712-5.

11. Bogaerts P, Galimand M, Bauraing C, Deplano A, Vanhoof R, De Mendonca R, et al. Emergence of ArmA and RmtB aminoglycoside resistance 16S rRNA methylases in Belgium. J Antimicrob Chemother. 2007;59(3):459-64.

12. Kacmaz B, Aksoy A. Antimicrobial resistance of enterococci in Turkey. Int J Antimicrob Agents. 2005;25(6):535-8.

13. Folster JP, Rickert R, Barzilay EJ, Whichard JM. Identification of the aminoglycoside resistance determinants armA and rmtC among non-Typhi Salmonella isolates from humans in the United States. Antimicrob Agents Chemother. 2009;53(10):4563-4.
14. Feizabadi MM, Maleknejad P, Asgharzadeh A, Asadi S, Shokrzadeh L, Sayadi S. Prevalence of aminoglycoside-modifying enzymes genes among isolates of Enterococcus faecalis and Enterococcus faecium in Iran. Microb Drug Resist. 2006;12(4):265-8.

15. Saifi M, Pourshafie MR, Eshraghian MR, Soltan Dallal MM. Antimicrobial resistance of Enterococci isolated from urinary tract infections in Iran. Iran Biomed J. 2008;12(3):185-90.

16. Moniri R, Ghasemi A, Moosavi SGA, Dastehgoli K, Rezaei M, Soares RO, et al. Virulence Gene's Relationship With Biofilm Formation and Detection of aac (6')/aph (2") in Enterococcus faecalis Isolated From Patients With Urinary Tract Infection. Jundishapur J Microbiol.2013;6(5).

17. Zhang Y, Zhou H, Shen XQ, Shen P, Yu YS, Li LJ. Plasmid-borne armA methylase gene, together with blaCTX-M-15 and blaTEM-1, in a Klebsiella oxytoca isolate from China. J Med Microbiol. 2008;57(Pt 10):1273-6.

18. Doi Y, Wachino J, Yamane K, Shibata N, Yagi T, Shibayama K, et al. Spread of novel aminoglycoside resistance gene aac(6')-Iad among Acinetobacter clinical isolates in Japan. Antimicrob Agents Chemother. 2004;48(6):2075-80.

19. Ma L, Lin CJ, Chen JH, Fung CP, Chang FY, Lai YK, et al. Widespread dissemination of aminoglycoside resistance genes armA and rmtB in Klebsiella pneumoniae isolates in Taiwan producing CTX-M-type extended-spectrum beta-lactamases. Antimicrob Agents Chemother. 2009;53(1):104-11.

20. Yu F, Wang L, Pan J, Yao D, Chen C, Zhu T, et al. Prevalence of $16 \mathrm{~S}$ rRNA methylase genes in Klebsiella pneumoniae isolates from a Chinese teaching hospital: coexistence of rmtB and armA genes in the same isolate. Diagn Microbiol Infect Dis. 2009;64(1):57-63.

21. Yu F, Chen Q, Yu X, Pan J, Li Q, Yang L, et al. High prevalence of plasmid-mediated quinolone resistance determinant aac(6')-Ibcr amongst Salmonella enterica serotype Typhimurium isolates from hospitalised paediatric patients with diarrhoea in China. Int J Antimicrob Agents. 2011;37(2):152-5.

22. Savic M, Lovric J, Tomic TI, Vasiljevic B, Conn GL. Determination of the target nucleosides for members of two families of 16S rRNA methyltransferases that confer resistance to partially overlapping groups of aminoglycoside antibiotics. Nucleic Acids Res. 2009;37(16):5420-31.

23. Yamane K, Wachino J, Suzuki S, Shibata N, Kato H, Shibayama K, et al.16S rRNA methylase-producing, gram-negative pathogens, Japan. Emerg Infect Dis. 2007;13(4):642-6.

24. Radhouani H, Poeta P, Goncalves A, Pacheco R, Sargo R, Igrejas G. Wild birds as biological indicators of environmental pollution: antimicrobial resistance patterns of Escherichia coli and enterococci isolated from common buzzards (Buteo buteo). J Med Microbiol. 2012;61(Pt 6):837-43.

25. Ho PL, Wong RC, Lo SW, Chow KH, Wong SS, Que TL. Genetic identity of aminoglycoside-resistance genes in Escherichia coli isolates from human and animal sources. J Med Microbiol. 2010;59(Pt 6):702-7.

26. Fracalanzza SA, Scheidegger EM, Santos PF, Leite PC, Teixeira LM. Antimicrobial resistance profiles of enterococci isolated from poultry meat and pasteurized milk in Rio de Janeiro, Brazil. Mem Inst Oswaldo Cruz. 2007;102(7):853-9.

27. Jackson CR, Fedorka-Cray PJ, Barrett JB, Ladely SR. Genetic relatedness of high-level aminoglycoside-resistant enterococci isolated from poultry carcasses. Avian Dis. 2004;48(1):100-7.

28. Salem-Bekhit MM, Moussa IMI, Muharram MM, Elsherbini AM, AlRejaie S. Increasing prevalence of high-level gentamicin resistant enterococci: An emerging clinical problem. Afr J Microbiol Res. 2011;5(31):5713-20.

29. Mohammadi F, Tabaraie B, Sadeghifard N, Ghafoorian S, Maleki A Davoodian E. Evaluation of drug resistance frequency among Entrococci faecium and E. faecalis strains and detection of VanA/B genes in vancomycin resistance isolated by PCR method in ilam and kermanshah hospitals. Sci J Ilam Uni Med Sci. 2011;19(2):1-7.

30. Vaziri F, Peerayeh SN, Nejad QB, Farhadian A. The prevalence of aminoglycoside-modifying enzyme genes (aac (6')-I, aac (6')-II, ant (2")-I, aph (3')-VI) in Pseudomonas aeruginosa. Clinics (Sao Paulo). 2011;66(9):1519-22.

31. Wachino J, Arakawa Y. Exogenously acquired $16 \mathrm{~S}$ rRNA methyl- 
transferases found in aminoglycoside-resistant pathogenic Gramnegative bacteria: an update. Drug Resist Updat. 2012;15(3):133-48

32. Xiao Y, Hu Y. The major aminoglycoside-modifying enzyme
AAC(3)-II found in Escherichia coli determines a significant disparity in its resistance to gentamicin and amikacin in China. $M i-$ crob Drug Resist. 2012;18(1):42-6. 